\title{
Linking edge effects and patch size effects: Importance of matrix nest predators
}

\author{
Pablo M. Vergara ${ }^{\mathrm{a}, *}$, Ingo Hahn ${ }^{\mathrm{b}}$ \\ a Departamento de Ingeniería Geográfica, Universidad de Santiago de Chile, Av. Lib. B. O’Higgins 3363, Santiago, Chile \\ ${ }^{\mathrm{b}}$ Animal Ecology and Biogeography Res. Group, Inst. Landscape Ecology, University of Münster, Robert-Koch-Str. 26-28, D - 48149 Münster, Germany
}

\section{A R T I C L E I N F O}

\section{Article history:}

Received 7 October 2007

Received in revised form 29 January 2009

Accepted 17 February 2009

Available online 14 March 2009

\section{Keywords:}

Matrix nest predators

Edge effect

Patch size

\begin{abstract}
A B S T R A C T
The edge effect is usually considered to be the proximate cause of area sensitivity in forest birds. We tested if birds nesting in large patches are less vulnerable to the edge effect using a simple model that assumes an increase in patch size reduces the probability of a matrix predator moving to the core areas of forest and that larger perimeter/area ratios result in a higher number of matrix predators per unit of area. The probability of a nest being successful decreased asymptotically with an increase in either the patch penetration distance of predators or predator density, but those effects were reduced when patch size was increased. Large patches have a lower probability of being affected by an Allee effect and they can function as sink habitats only if penetration distance and predator density are largely increased. However, the transition from an Allee effect to a sink condition occurs with a small increase in penetration distance and predator density. Since birds nesting in large patches are less vulnerable to an increase in matrix predator populations, persistence of bird populations may be possible by increasing the size of habitat patches that can act as source populations.
\end{abstract}

(c) 2009 Elsevier B.V. All rights reserved.

\section{Introduction}

Edge-dependent nest predation is an important cause of nest failure for several forest bird species, eventually resulting in population decline in fragmented forest landscapes (Wilcove, 1985; Bohning-Gaese et al., 1993; Lahti, 2001). Forest areas close to edges may result in unsuitable habitat conditions, reducing individual fitness and population size of breeding birds (Donovan et al., 1997; Flaspohler et al., 2001). Additionally, predators can cause an Allee effect (Allee, 1931) because predation rates tend to increase at low nest densities (Levins and Schultz, 1996; Gascoigne and Lipcius, 2004; Berec et al., 2007). The nest predation edge effect can make the growth rate negative, resulting in sink populations where mortality exceeds recruitment (Pulliam and Danielson, 1991; Thompson et al., 2002; Lloyd et al., 2005). Moreover, the Allee effect could be amplified in fragmented landscapes because individuals inhabiting small fragments can experience a reduction in their survival or difficult in finding a mate (e.g. Lamberson et al., 1992).

The consequences of the edge effect on bird populations are largely influenced by the link between patch characteristics and the species-specific characteristics of predators (e.g. Deng and Gao, 2005; Storch et al., 2005; Vergara, 2005). The magnitude of the edge effect is expected to increase when patch size decreases (holding patch shape constant), due to an increase in the perimeter/area

\footnotetext{
* Corresponding author. Tel.: +56 27182227.

E-mail address: pablo.vergara@usach.cl (P.M. Vergara).
}

ratio (Saunders et al., 1991; Murica, 1995). This means that birds nesting in small forest patches are more exposed to nest predators appearing from the matrix (e.g. Andrén and Angelstam, 1988), although field studies have not always supported this hypothesis (e.g. Huhta et al., 1998; Keyser et al., 1998; Matthews et al., 1999). Most nest predator species are generalist foragers inhabiting primarily the matrix which corresponds to the prevailing habitat in the landscape (usually an anthropogenic habitat) that surrounds patches of native habitat. Matrix predators are mostly birds (e.g. corvids and caracaras), small mammals (e.g. squirrels and rodents), and small or medium size carnivores such as foxes or raccoons (Andrén, 1992; Söderström et al., 1998; Seymour et al., 2004; Vergara, 2005; Barding and Nelson, 2008). The association between edge effect and patch size is difficult to test because patch geometry tends to become more complex as forest fragmentation increases (Fernández et al., 2002; Fletcher, 2005). Nevertheless, a fundamental factor determining such an association is the speciesspecific response of matrix nest predators to forest edges (Cantrell et al., 2002; Mazgajski and Rejt, 2005).

Two important factors influencing the edge effect are the movement behavior of matrix predators in the forest edge and their abundance in the matrix habitat (Andrén and Angelstam, 1988; Chalfoun et al., 2002). Since some forest structures can act as a barrier to the movement of species that live primarily in anthropogenic habitats, the permeability of boundaries to predators may greatly affect the spatial predation pattern within forest patches (Wiens, 1992; Pasitschniak-Arts and Messier, 1995). Consequently, the distance which predators are able to penetrate into forest patches is an 
important variable in explaining the distance over which the gradient in nest predation extends within a forest (Angelstam, 1986; Dijak and Thompson, 2000; Storch et al., 2005). Furthermore, several studies have shown that the levels of nest predation at forest edges are positively correlated with predator density in the surrounding matrix (Angelstam, 1986; Picman, 1988; Yahner, 1996). For the sum of these findings we expect that nest success probability will decrease in small patches due to two reasons: (1) an increase in patch size involves an increase in core areas of forest, i.e., sites that are far enough away from forest edges and hence the presence of matrix nest predators is less probable; and (2) an increase in patch size involves that less predators per unit of area enter from the surrounding matrix because matrix predators penetrate patches through the patch perimeter and the perimeter/area ratio decreases with area.

In this study we aim to develop a model to determine if birds nesting in large patches are less vulnerable to the edge effect in a scenario where nest predators enter forest patches from the surrounding matrix habitat. This model is expected to allow testing whether the effect of both predator density and predator movement on nest success and population dynamics decreases with patch size. To date, the few models that have explored how the link between edge effect and patch size is affected by the movement and density of matrix predators have not addressed explicitly how these mechanisms affect the nest success (e.g. Cantrell et al., 2001, 2002). In this study we aim to determine how the edge effect reduces nest success of a particular forest bird species, and how this decrease in nest success may cause an Allee effect as well as reduce the local population growth rate to a critical replacement level.

\section{Methods}

\subsection{Nest success model}

We developed a simple deterministic model in which the probability of nest success and the population dynamics in a patch is determined by nest predation. We consider a single forest-specialist bird species that nests in forest patches surrounded by an open habitat matrix, and whose nest success is determined by nest predation (Fig. 1). We also assume that all matrix nest predators belong to the same species, hence they have basically the same foraging behavior and a diet composed fundamentally of a single prey species inhabiting the matrix habitat. In consequence, forest patches are secondary foraging habitats for matrix predators and thus nest predation within patches is incidental (Vickery et al., 1992; Schmidt et al., 2001). As a consequence of these assumptions, the model considers that bird density does not affect the predator population dynamics, which is determined by ecological processes in the matrix (e.g. Gates and Gysel, 1978; Pasitschniak-Arts and Messier, 1995).

For a bird nesting at a distance $x$ from the edge of a patch $i$ with a density $n$, the probability of nest success depends on the probability that a nest does not survive a predator incursion within the patch during a daily period $\left(u_{x, i}\right)$, which can be estimated as:

$u_{x, i}=g(x) f(x) b(n)$,

and depends on three functions: $g(x)$, which is the penetration probability of a predator up to the nest location $(x) ; f(x)$, the probability that a nest is located at a distance $x$ from the edge; and $b(n)$, the conditional probability that a brood is eaten by a predator given that the predator moved to this nest site from the edge.

We assume that penetration distances of matrix predators into forest fragments follow a negative exponential distribution since nest predation rates and predator density tend to decline exponentially with distance from the patch edge (Angelstam, 1986; Cantrell et al., 2001, 2002). Given this movement behavior, the probability of a predator moving a certain distance from the patch edge $(x)$ is

$p(x \mid \theta)=\frac{1}{\theta} \exp ^{(-x / \theta)}$

where parameter $\theta$ scales the effect of distance to movements within patches (Table 1). Eq. (2) provides an estimate of the penetration probability of a matrix nest predator, $g(x)$ in Eq. (1). The value of $\theta$ is dependent on the degree to which predator movements are constrained by forest structures and other ecological mechanisms related to forest edges, and hence greater values of $\theta$ imply greater penetration distances to interior forest locations. Ecotone habitats located on forest edges may be suitable sites for predator incursions, contrasting with forest core conditions (e.g. Gates and Gysel, 1978). Furthermore, the longer the incursion distance, the longer the time spent by a matrix predator in returning to the matrix, which may result in an important energy cost when the nest finding rate is low and the vegetation structure is unsuitable

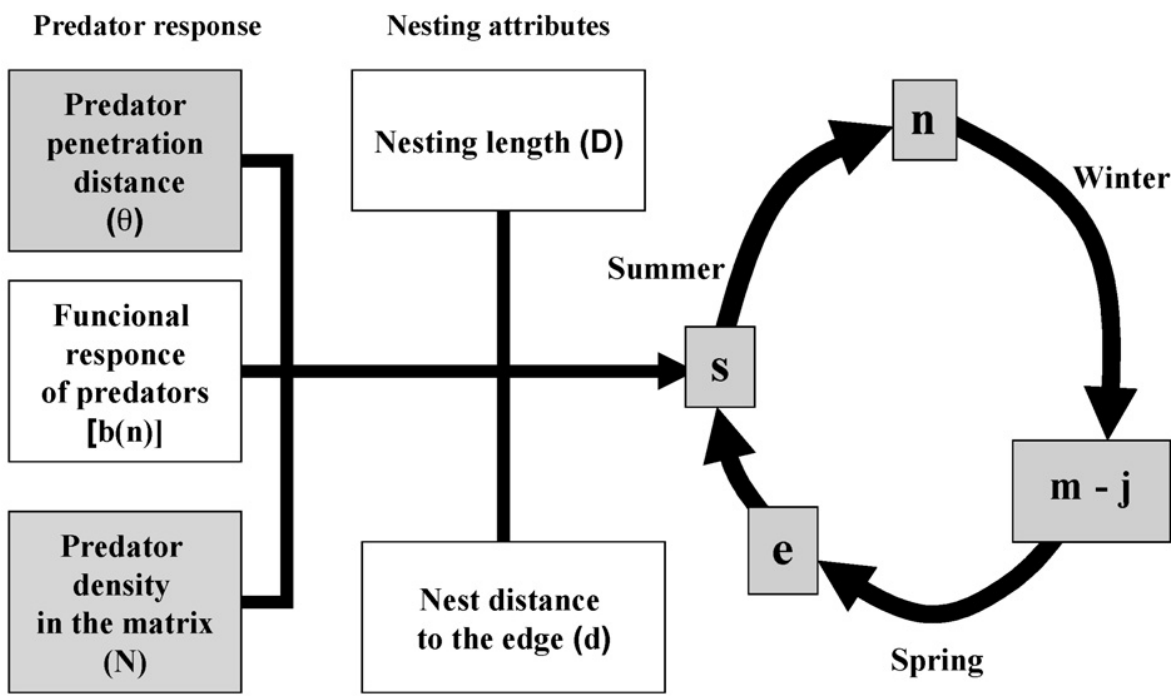

Fig. 1. The annual life cycle of a typical passerine species of temperate forests. Adults lay clutches of size $e$ that survive the breeding period with probability $s$. Adult and juvenile individuals survive the winter with probability $1-m$ and $j$, respectively. Population size $(n)$ is recorded at the end of the breeding period. Edge effect on nesting success is accounted for by predator responses and nesting attributes. The effect of the numerical and behavioral responses of predators to edge habitats (grey boxes) on bird populations was assessed using a model (see text). 
Table 1

Summary of parameters used to model the edge effect on nest success and growth rate of a bird population (see Fig. 1).

\begin{tabular}{|c|c|}
\hline Parameter & Description \\
\hline$\theta$ & Mean patch (or edge) penetration distance of a predator (m) \\
\hline$d_{i}$ & $\begin{array}{l}\text { Patch radius or maximum distance measured from the patch } \\
\text { centroid to its edge (m) }\end{array}$ \\
\hline$\alpha$ & $\begin{array}{l}\text { Attack rate of a predator (probability that the predator finds } \\
\text { and eats a brood) }\end{array}$ \\
\hline$T_{h}$ & Handling time $\left(T_{h}\right)$ \\
\hline$N$ & Predator density in the matrix (number/ha) \\
\hline$P$ & Number of matrix predators making incursions into the patch \\
\hline$D$ & Length of nesting period (days) \\
\hline$\psi$ & Number of daily incursions into the patch per matrix predator \\
\hline$s_{i}$ & Probability of nest success in a patch \\
\hline$j_{i}$ & $\begin{array}{l}\text { Juvenile survival: probability that a young female will survive } \\
\text { until the next breeding season }\end{array}$ \\
\hline$m_{i}$ & $\begin{array}{l}\text { Adult mortality: probability that an adult female will survive } \\
\text { until the next breeding season }\end{array}$ \\
\hline$e_{i}$ & Expected clutch size of female broods (eggs/nest) \\
\hline
\end{tabular}

for movement. Consequently, this model does not consider the case in which nest penetration distance is influenced by nest density. Empirical studies have suggested that the mean distance in which matrix nest predators search for nests into a habitat patch ranges between 50 and $200 \mathrm{~m}$ (e.g. Paton, 1994; Söderström et al., 1998). Furthermore, $\theta$ could be estimated using either binomial models predicting the effect of edge distance on daily nest survival rates or from radio-tracking data (Barding and Nelson, 2008).

We assumed that nest density is not affected by distance from the edge since birds neither detect nor behaviorally respond to the predator-occupied space, an assumption that simplifies model predictions and its mathematical formulation. Although this assumption is weakly supported for some bird species (e.g. Gates and Gysel, 1978; Flaspohler et al., 2001), our interest in modelling the edge effect is focused on understanding the response of matrix nest predators to patch edges. We also assume that patches are circular with radius $d_{i}$. Circular patches simplify the study of the edge effect because all points on the circumference are equidistant from the center, minimizing variability in edge distance. In circular patches, however, a larger proportion of nests is located in core habitat, in comparison to irregular-shaped patches. In spite of this limitation, we did not consider alternative, and more realistic, patch shapes (e.g. elliptical or irregular) because we could not find a model solution for the expected nest success in a patch (see below). Considering these assumptions, the probability of a nest being located at a distance $x$ from the edge, $f(x)$, is a probability density function of nest distance from the patch edge (i.e., $\int_{0}^{d_{i}} f(x) \partial x=1$ ), which can be estimated as:

$f(x)=\frac{2\left(d_{i}-x\right)}{d_{i}^{2}}$.

To determine conditions under which nest predation causes an Allee effect and reduces local population growth rate below a critical replacement level, we assumed that predators follow a type II functional response (sensu Holling, 1959) because it can make population growth rate negative at low prey densities (Cantrell et al., 2001; Gascoigne and Lipcius, 2004). Considering this predator behavior, the probability that a brood or clutch is consumed over a daily period by a predator $(b[n]$ in Eq. (1)) can be estimated as:

$b(n)=\frac{\alpha}{1+T_{h} \alpha n}$ for $0>\alpha \leq 1$,

with parameters $\alpha$ and $T_{h}$ giving the attack rate and the handling time of predators, respectively (Table 1). Attack rate is the rate at which predator search for nests and handling time is the time required for a predator to eat a single clutch (Holling, 1959). Both parameters can be estimated from experimental field data by regressing nest survival rates on nest density and predator density (e.g. Abrams and Ginzburg, 2000; Miller et al., 2006). Consequently, this model could be fitted to field data of nest survival by adjusting these parameters. For simplicity, we assume that the factors determining attack rate $(\alpha)$ are constant on each patch.

The probability of a nest not surviving a predator incursion $\left(u_{x, i}\right)$ is given by substituting Eqs. (2)-(4) in Eq. (1). Thus, the spatially averaged probability of a nest not surviving a matrix predator incursion in a patch $\left(\hat{u}_{i}\right)$ can be estimated as:

$\hat{\mathrm{u}}_{i}=\int_{x=0}^{d_{i}} u_{x, i} d_{x}=\frac{2 \alpha \theta^{2}\left(\exp ^{\left(-d_{i} / \theta\right)}+\left(d_{i} / \theta\right)-1\right)}{\left(1+T_{h} \alpha n\right) d_{i}^{2}}$.

The model in Eq. (5) is a method for solving the mean of multiple nest predation events occurring during a single day by a predator rather than a mechanistic model of nest predation in edge habitats. Therefore, this model does not consider probable temporal and spatial changes in nest density during a day within a single patch. The nest success probability is a composite function of $\hat{u}_{x, i}$, the number of matrix predators making incursions into the patch $(P)$, the number of days in the nesting cycle $(D)$, and the number of daily incursions per predator ( $\psi$, Table 1 ). Thus, if predators make $P \psi$ daily incursions within a patch, and assuming a nesting cycle of $D$ days, the probability of a nest surviving to $P \psi D$ predator incursions results in an estimate of the probability of nest success in a patch $\left(s_{i}\right.$, see Table 1$)$, which can be expressed as:

$s_{i}=\left(1-\hat{\mathrm{u}}_{i}\right)^{P \psi D}$.

In Eq. (6) the term $\left(1-\hat{\mathrm{u}}_{i}\right)^{P \psi}$ is similar to the daily nest survival rate estimated using Mayfield's method (Mayfield, 1975). Consequently, $s_{i}$ is the daily nest survival powered to the length of the exposure period in days $(D)$, and therefore an estimate of the proportion of breeding females that have nests with hatched eggs, or that produce fledged young in a patch. The number of daily incursions per predator $(\psi)$ is a species-specific parameter scaling with the time that a generalist predator spends searching and foraging in patches of alternative habitat. The latter parameter can be derived from either radio-tracking studies or field observational data of matrix predators moving in fragmented habitats (see, e.g. Seymour et al., 2003; Marzluff et al., 2005 for the use of such methodologies). Parameter $P$ corresponds to the number of matrix predator territories that are covered or intercepted by the patch edge (in this case the perimeter), i.e., an estimate of the expected number of predators that potentially could enter from the matrix into the patch. Considering the latter assumption and assuming no overlapping territories among predators, $P$ can be approximated as:

$P=2 N^{0.5} d_{i}^{-1}$,

where $P$ is a function of predator density in the matrix $(N)$ and patch radius (Table 1). Depending on predator species, predator density in the matrix can be estimated using different sampling approaches, including visual observations, DNA analysis of fecal samples, or trapping (e.g. Andrén, 1992; Kays et al., 2008; see also Chalfoun et al., 2002). Predator density can vary significantly over time, such as populations of small mammals (Ostfeld et al., 1996; Schmidt et al., 2001). Accordingly, if $N$ remains constant, then $P$ is directly proportional to the perimeter/area ratio for a circle. Nonetheless, the number of daily predator incursions $(P \psi)$ in a patch is minimized by the model because it assumes that patches are circular, representing the maximum perimeter/area ratio.

\subsection{Population effects}

To assess how nest predation affects population dynamics, we derived an expression of the per-capita growth rate (using Eq. (6)) for a population of adult female birds $\left(r_{i}\right)$ living in patch $i$, which 
does not consider emigration-immigration, and is a continuous function in $n$ defined by:

$r_{i}(n)=s_{i}(n) j_{i}(n) e_{i}-m_{i}$

where $j_{i}$ corresponds to juvenile survival, $e_{i}$ is the expected clutch size, and $m_{i}$ is the mortality rate of adults (Table 1 ). As we considered a non-biased sex ratio, the number of nests equals the number of adult breeding females. Survival of adults and juveniles was assumed to be independent of edge distance. We also assume that juvenile survival is an important process regulating local population, since juveniles experience high predation risk during the post-fledging period (Naef-Daenzer et al., 2001). Thus, juvenile survival $\left(j_{i}\right)$ was modelled as a negative density-dependent process defined by $j_{i}=1 /\left(1+n_{i}\right)$, with $j_{i}$ being maximum at density zero $\left(j_{i}\left[n_{i}=0\right]=1\right)$. Juvenile and adult survival rates are usually estimated from recaptures of previously marked individuals or recovery of dead birds (Schaub and Pradel, 2004).

Mortality of adults $\left(m_{i}\right)$ was initially assumed to be density independent (e.g. Pulliam, 1988). However, adult survival may be negatively associated with nest survival because lower nest success may permit more investment in adult survival until the next reproductive event and because of the existence of a negative relationship between nest concealment and adult survival (Wiebe and Martin, 1998; Ghalambor and Martin, 2001; Miller et al., 2007). Therefore, in order to relax this assumption, and for simplicity, we derived an expression of the per-capita growth rate $[r(n)]$ by including a linear trade-off between adult and nest survival (e.g. Martin, 1993). Thus, adult mortality in patch $i$ was defined as $m_{i}\left(n_{i}\right)=m_{b} s_{i}\left(n_{i}\right)$, with $m_{b}$ being the adult mortality of successful breeding birds.

The model given in Eq. (7) provides a basis for making inferences about the effect of nest predation upon a local bird population. Consequently, we used this deterministic model to estimate the minimum values of $N$ and $\theta$ necessary to generate an Allee effect (hereafter called the "Allee threshold") and a sink condition (hereafter called the "sink threshold").

Two conditions are necessary for an Allee effect to occur. First, the per-capita growth rate must reach its peak at a positive population value, and second, population size must drop below this population value. The first condition is dependent on deterministic factors (such as parameters $N$ and $\theta$ ), while the second condition depends basically on stochastic factors that affect population dynamics (Courchamp et al., 1999). Since a type II functional response can result in an unstable point at low density (e.g. Cantrell et al., 2001), we find the Allee threshold by determining the values of $\theta$ and $N$ where the growth rate at density zero equals zero (i.e., $r[0]=0)$, since the slope of $r(0)$ is positive [i.e., $d r(n=0) / d n>0$ ]
(Appendix B). The Allee threshold gives the parametric conditions under which an unstable point appears at low density values, and hence is an estimate of how likely a population is to extinction in stochastic environments (Courchamp et al., 1999). Since in sink populations the per-capita growth rate is negative for any density value (i.e., $r(n)<0$ on $[0, \infty]$ ), where $r=[d n / d t] / n$ ) (Pulliam, 1988), a criterion to establish a sink threshold is to determine parameter values at which the value of the maximum growth rate $\left(r_{\max }\right)$ equals zero (Appendix A). The sink threshold allows the distinction of sinks from either pseudo sinks or sources since in both of them $r_{\max }>0$ at least in some interval of $n$ (Watkinson and Sutherland, 1995).

The values of parameters $\alpha, \gamma, m, \psi$ and $D$ were kept constant in all the analyses because they did not affect the general results, i.e., the position of the thresholds in the parametric plots were similar when these parameters were changed. The attack rate $(\alpha)$ and the handling time of predators $\left(T_{h}\right)$ were assumed to be 0.5 and 1 , respectively, because they are in the range of values observed for generalist predators and are commonly used in modelling studies (e.g. Cantrell et al., 2001; Jeschke et al., 2002; Abrams, 2004). Based on recapture data of forest bird species living in fragmented landscapes, we assumed an overwinter mortality $(m)$ of adult females of $30 \%$ (e.g. Zanette et al., 2000). The number of daily incursions per predator in a patch $(\psi)$ was set to 10 because this value has been observed for avian nest predators such as the Chimango Caracara (Milvago chimango) in fragments of temperate forest (Vergara; unpublished). The nesting period length $(D)$ was assumed to be 30 days, a characteristic time period for several forest bird species (Martin and Li, 1992). Analyses were done using the R 2.1.1 software (R Development Core Team, 2005).

\section{Results}

\subsection{Nest success}

Nest success decreases asymptotically when penetration distance $(\theta)$, and predator density $(N)$ are increased (Fig. 2 ). Thus, when either $\theta$ or $N$ reach zero, the nest success approaches unity, indicating that the nest predation edge effect depends on both parameters (Fig. 2). However, the effect of $\theta$ and $N$ on nest success decreases with an increase in bird density (Fig. 2).

The negative effect of penetration distance $(\theta)$ and predator density $(N)$ on nest success is reduced when either patch size or nest density increase (Figs. 3 and 4). Consequently, nest success in small patches is notoriously increased when nest density is high (e.g. the 0.125 ha patch shown in Fig. 3).
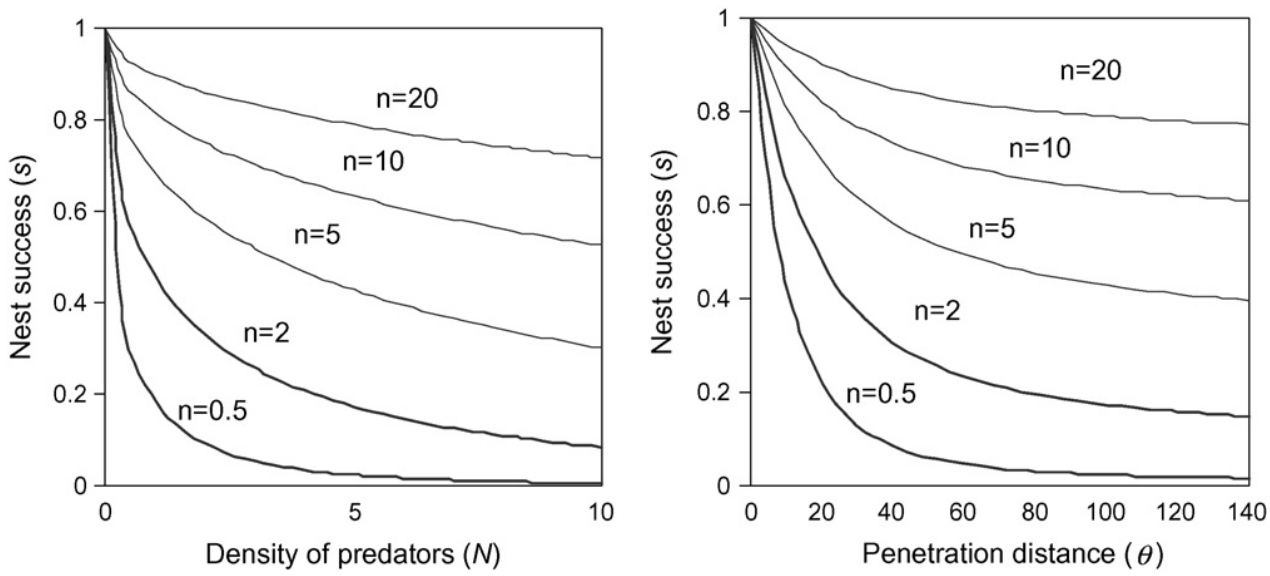

Fig. 2. The negative effect of predator density $(N$, on the left) and penetration distance $(\theta$, on the right) on nest success probability for five different nest densities ( $n)$ in a 3-ha patch. 

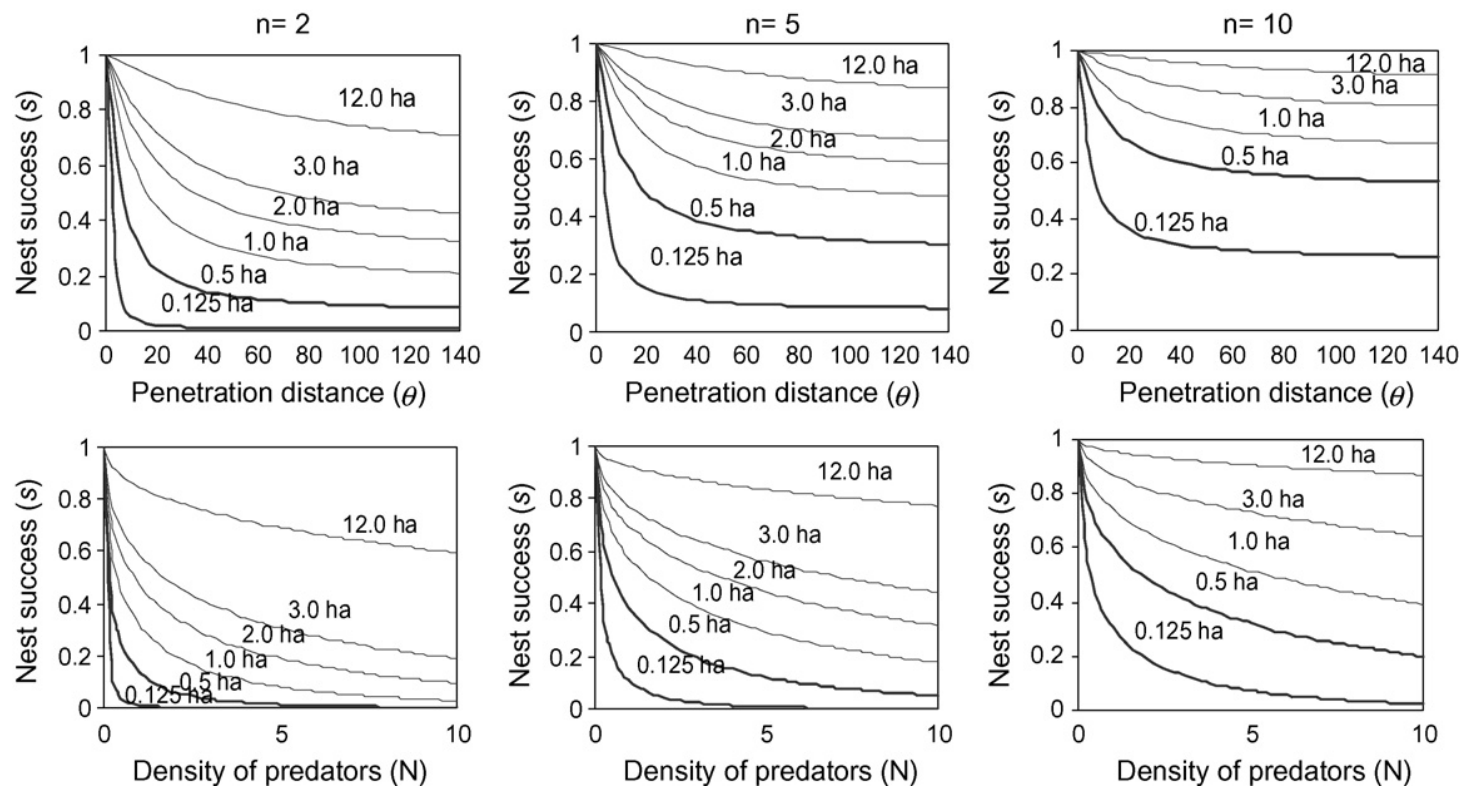

Fig. 3. The negative effect of predator density ( $N$, below) and penetration distance $(\theta$, above) on nest success probability for six different patch sizes and three different nest densities: low $(n=2)$, medium $(n=5)$, and high density $(n=10)$.
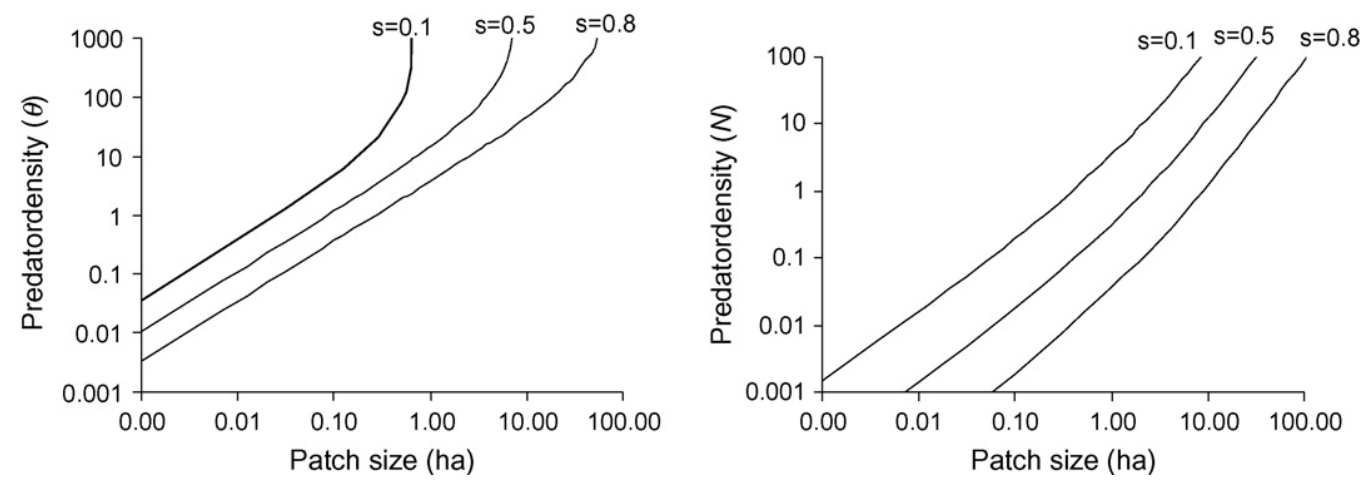

Fig. 4. The positive relationship between patch size and both predator density ( $N$, on the right) and penetration distance $(\theta$, on the left) required to get an arbitrary probability of nest success on a log-log plot for three different values of nest success probability $(s)$.

\subsection{Population effects}

Edge effect caused by matrix nest predators strongly affects the dynamics of bird populations. When a linear trade-off between adult and nest survival is assumed, the per-capita growth rate $(r)$ is characterized by a linear density dependence with a unique equilibrium density $\left[n^{*}=\left(e-m_{i}\right) / m_{i}\right.$, for $\left.r=0\right]$. When mortality is assumed

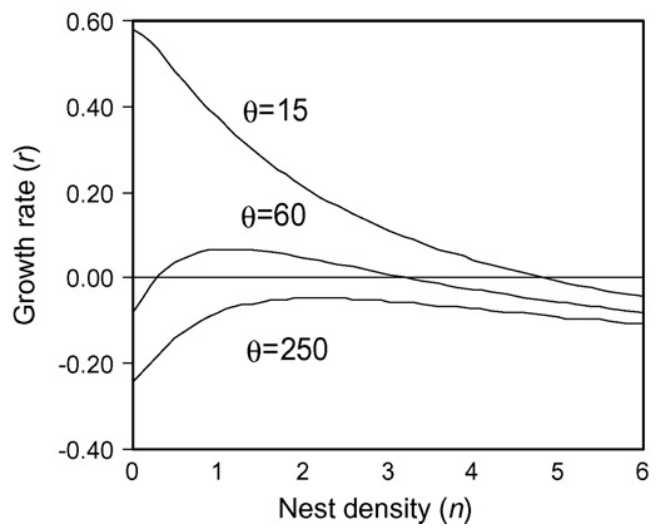

to be constant, however, two equilibrium points emerge in the dynamics (Fig. 5). With low values of penetration distance $(\theta)$ and predator density $(N)$ the per-capita growth rate $(r)$ decreases in an almost linear way as the nest density increases, and reaches a maximum value at density zero $\left(n_{i}=0\right)$ (Fig. 5$)$. However, with an increase in the values $\theta$ and $N, r$ tends to be maximized at intermediate values of density (in the $[0, K]$ interval), where $K$ is the carrying capacity),

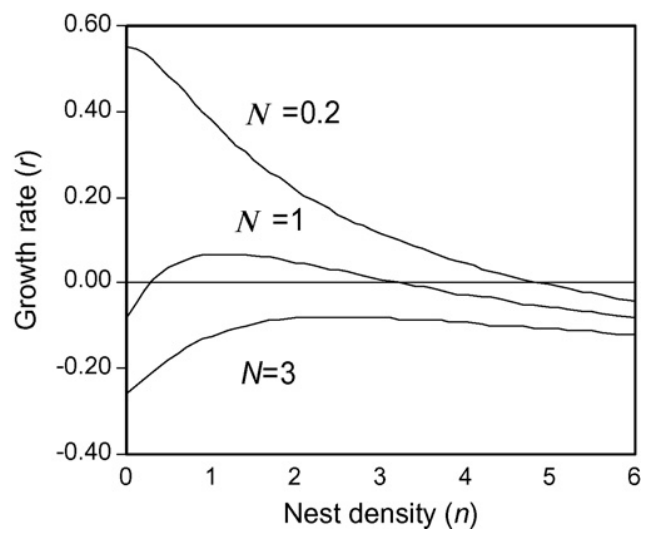

Fig. 5. Per-capita growth rate $(r)$ as a function of nest density in a 3 ha patch with different values of both penetration distance $(\theta$, on the left) and predator density ( $N$, on the right). 


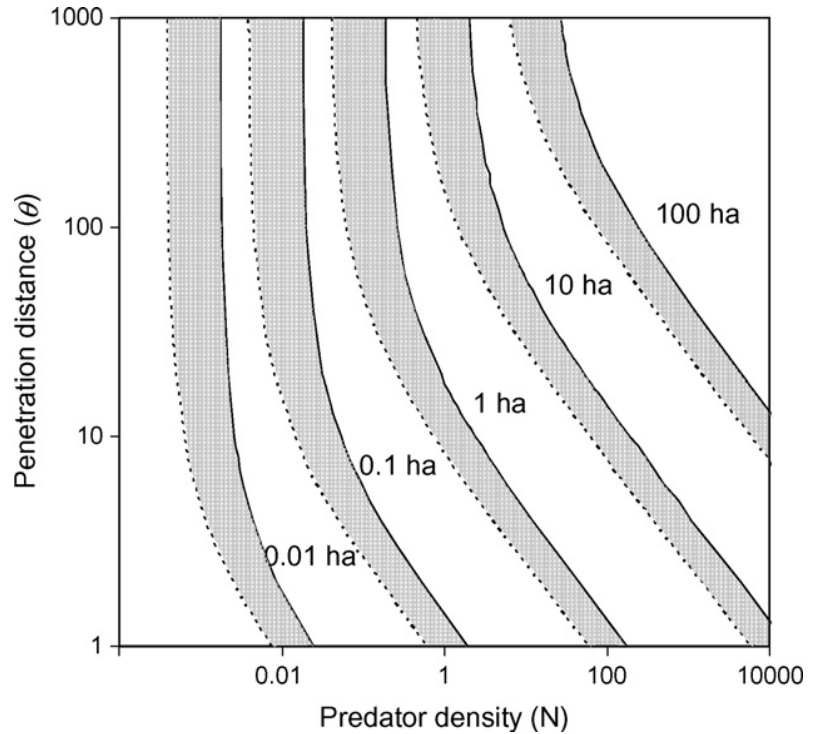

Fig. 6. Parametric plot between penetration distance $(\theta)$ and density of predators $(N)$ for different patch sizes (ha). Solid lines represent sink thresholds, i.e., minimum values of $\theta$ and $N$ making the maximum growth rate negative $\left(r_{\max }<0\right)$. Dashed lines represent Allee thresholds, i.e., minimum values of $\theta$ and $N$ generating an Allee effect. The shaded area represents the Allee region.

resulting in an unstable equilibrium point at low density which triggers an Allee effect (Fig. 5). Furthermore, when the values of $\theta$ and $P$ undergo an important increase, $r$ becomes negative for any density value, and the population may function as a sink (Fig. 5).

The nest predation edge effect generates a sink threshold which is established by a negative relationship between $\theta$ and $N$ (solid lines in Fig. 6). The sink threshold defines two different parametric areas determining the population status: the sink region (on the right of the threshold curve) and the source or pseudo-sink region (on the left of the threshold curve; Fig. 6). The sink threshold is linear on a $\log$-log plot except for large values of $\theta$, where the threshold becomes asymptotic for predator density values $(N)$, indicating that below these $N$ values populations will not function as sinks (Fig. 6). Thus, an increase in either $\theta$ or $N$ will increase the likelihood that a population will function as a sink, at least if one of the parameters is maintained constant.

The nest predation edge effect also generates an Allee threshold, which is established by a negative relationship between $\theta$ and $N$ (dashed lines in Fig. 6). The Allee threshold has a similar shape as the sink threshold but it occurs at lower values of $\theta$ and $N$ (Fig. 6), indicating that lower values of $\theta$ and $N$ are necessary to generate an Allee effect (Fig. 6). The parametric area located between the Allee and the sink thresholds, called the "Allee region", defines the nest predation conditions under which the local population exhibits an Allee effect (Fig. 6).

An increase in patch size increases the values of $\theta$ and $N$, generating both a sink and an Allee threshold, moving those threshold curves to the right of the parametric plot (Fig. 6). However, on a $\log -\log$ plot the size of the Allee region does not change with patch size, indicating that the parametric intervals on which populations are affected by an Allee effect are proportional to the patch size (Fig. 6). Consequently, the effects of either the penetration distance $(\theta)$ or predator density $(N)$ on population dynamics are dependent on patch size, with large values of both parameters being required to generate an Allee effect or to reduce population growth rate below a critical replacement level (Fig. 7). The positive relationship between patch size and threshold values of $\theta$ and $N$ is nearly linear on a $\log -\log$ plot for both the Allee and the sink threshold. However, threshold $\theta$ values become asymptotic for large patch sizes, indicating that sufficiently large patches will never be affected by an Allee effect, or will function as sinks, if penetration distances are increased (Fig. 7).

\section{Discussion}

Our model suggests that the edge effect results in a patch size effect if at least three basic conditions are met: (1) nest predators are habitat generalist species associated with the surrounding matrix habitat; (2) forest boundaries are permeable to matrix predators; (3) predator density in the matrix is large enough to affect nest success.

One of the most widely accepted mechanisms proposed to explain the edge effect is the distance which predators penetrate to the patch-interior sites. In our model the patch penetration distance is only a per-capita measure, and thus the width of the edge habitat influenced by matrix predators is a composite function of the movement behavior (i.e., penetration distance) and the numerical response of predators (i.e., predator density). Consequently, a large abundance of matrix nest predators constitutes an alternative explanation for higher levels of edge effect (e.g. Small and Hunter, 1988; Wilcove, 1985). This means that predators with high movement ability within patches may have a negligible effect on nest success and population dynamics if their abundance in the matrix is low (see Fig. 6). In contrast, a large abundance of generalist predators in the matrix might have no effect on nest success or local population when the edges are impermeable to
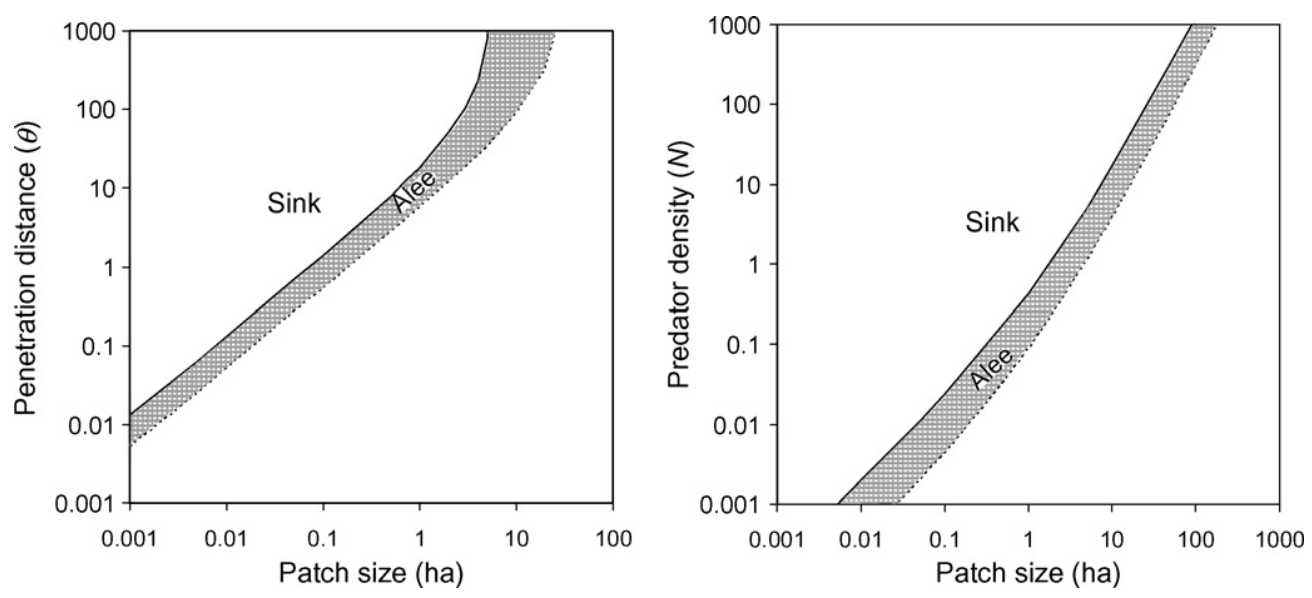

Fig. 7. The positive relationship between patch size and both predator density ( $N$, on the right) and penetration distance $(\theta$, on the left) required to generate an Allee effect (dashed line and shaded area) or to reduce population growth rate below a critical replacement level (continuous lines). 
the movement of matrix predators (Fig. 6). Understanding the compensatory effect between penetration distance and predator abundance may be crucial for planning conservation strategies of breeding birds in fragmented landscapes.

The link between patch size effect and edge effect results from the spatial distribution of matrix predators within patches and depends on the geometric components of patches. Thus, the effect of penetration distance decreases in large patches because large patches have longer radii, and hence the probability that a matrix predator will move to areas close to the patch centre is low in comparison to small sized patches. Consequently, only core areas at more than a critical distance from the edge are suitable sites for successful breeders, and hence the likelihood that a local population will function as a sink decreases with patch size, as has been suggested by empirical studies of birds living in fragmented landscapes (e.g. Donovan et al., 1997; Manolis et al., 2002; Perkins et al., 2003). Moreover, since the probability that a bird nests in a core habitat area increases as patch size increases (because large patches have proportionally more core habitat), a large fraction of clutches will be exposed to matrix nest predators in small patches (e.g. see Fig. 4). However, nest success predicted by our model can be underestimated if the assumption of homogeneous nest density within a patch is violated. This can happen if the number of nests predated near the perimeter increases as a consequence of the greater activity of predators near edges.

The ratio of edge-to-interior habitat may be a better predictor of area sensitivity in birds than patch size per se (Davis, 2004). Large patches may intercept a greater number of predator territories in the matrix since they have longer edge lengths. However, the number of predators per unit area that a patch may eventually contain (if predators enter patches) decreases with patch size, since this number is proportional to the perimeter/area ratio. Therefore, by decreasing the perimeter/area ratio, an increase in patch size reduces the effect of predator density on nest success. Consequently, birds nesting in large patches are less vulnerable, or more resilient, to an increase in predator populations. The positive effect of the perimeter/area ratio on nesting birds may be important in landscapes where populations of generalist predators are highly variable in time due to variability in weather conditions, disturbances, and resource availability (e.g. Jaksic et al., 1997). Model predictions, however, should be taken with caution because circular patches are less exposed to the edge effect. Despite its theoretical nature and the validity of its underlying assumptions, the model presented here could be used as a baseline for analyzing a wide range of ecological problems, such as determining whether bird populations are likely to experience an Allee effect or establishing the minimum patch size needed to support viable local populations of woodland birds.

Model results indicate that at the local scale, predators generate an Allee effect, and in the extreme situation, they can lead viable populations to become sink habitats. The Allee effect is most likely to appear if adult mortality is not influenced by nest success because high nest predation rates at low densities are compensated by large adult survival rates. Furthermore, the Allee region is shown to be relatively narrow at logarithmic scale, and hence the transition from an Allee effect to a sink occurs with a small decrease in $\theta$ and $N$. Consequently, the Allee effect may not be easily detected in local bird populations if predator species undergo high fluctuations in population size or penetaration distance, which should be further explored using this model. Since populations exhibiting an Allee effect can be considered as potential sinks because they will become extinct at low densities (Courchamp et al., 1999), an important application of this model is the use of long term data on both predator and bird density to determine the critical population size under which the population can experience an Allee effect.
Populations outside the sink and the Allee regions might act as sources when immigration is successful and when the emigration rate does not reduce significantly the per-capita growth rate (Amarasekare, 2004). Those population consequences of nest predation are highly dependent on patch size. An increase in patch size increases nest success, reducing the probability of populations becoming sinks or having an Allee effect because predators have a lower chance of moving to core areas and the number of predators per unit of area decreases with patch size. Therefore, persistence of bird populations vulnerable to the edge effect may be possible by increasing the size of habitat patches which can act as source populations.

\section{Acknowledgements}

This study was financed mainly by the postdoctoral Fellowship FONDECYT 3060083 and Dicyt 02-0895SC. We express our gratitude to Jan O. Nyström (Swedish Museum of Natural History), Lillian Harris and Samy Atala (U. de Santiago) for suggestions and improvements in the English language.

\section{Appendix A}

Using Eq. (7) a sink threshold is estimated by finding out the parametric conditions under which the maximum growth rate equals zero $\left(r_{\max }=0\right)$. For a predation edge effect $(s(0)<1)$ a sink threshold occurs when

$\exists ! n$ in $I R^{+}, \quad \frac{\partial r}{\partial n}=\left.0 \wedge \frac{\partial r}{\partial n}\right|_{n=0}>0$

where the derivative of Eq. (8) is

$\frac{\partial r}{\partial n}=\frac{e s(n)}{(n+1)}\left(\frac{\gamma u(n) P D \psi}{(1-u(n))(\gamma n+1)}-\frac{1}{n+1}\right)$,

which is maximized at:

$\frac{\partial \mathrm{r}}{\partial n}=0=\left(\frac{\gamma u(n) P D \psi}{(1-u(n))(\gamma m+1)}-\frac{1}{n+1}\right)$,

and at density zero it can be expressed as

$\left.\frac{\partial r}{\partial n}\right|_{n=0}=\frac{\gamma \hat{\mathbf{u}}(0) P D \psi}{1-\hat{\mathbf{u}}(0)}-1$.

Parameter values satisfying the above threshold conditions were found by means of a numerical iteration procedure in the following sequence: (1) for each parameter combination we found the density value at which the growth rate is maximized $\left(n\left(r_{\max }\right)\right)$ by using an optimization procedure; $(2)$ we replaced $n\left(r_{\max }\right)$ in the $r(n)$ function and estimated the value of $r_{\max }$; (3) we repeated steps 1 and 3 until the value of the expression $\left|r_{\max }(n)\right|$ was minimized.

\section{Appendix B}

Using Eq. (8), the Allee threshold is estimated by finding out the parametric conditions under which $r(0)=0$ and $\partial r /\left.\partial n\right|_{n=0}>0$ are met (see Appendix A for this derivation). We defined an expression for predator density $(N)$ as a function of penetration distance $(\theta)$ according to

$N=\left[\frac{d[\log (m)-\log (e)]}{2 D \psi \log (1-\hat{\mathrm{u}}(0))}\right]^{2}$

\section{References}

Abrams, P.A., 2004. When does periodic variation in resource growth allow robust coexistence of competing consumer species? Ecology 85, 372-382. 
Abrams, PA., Ginzburg L R, 2000. The nature of predation:prey Dependent, ratio dependent or neither? Trends in Ecology and Evolution 15, 337-341.

Allee, W.C., 1931. Animal Aggregations. A Study in General Sociology. University of Chicago Press, Chicago.

Amarasekare, P., 2004. The role of density-dependent dispersal in source-sink dynamics. Journal of Theoretical Biology 226, 159-168.

Andrén, H., 1992. Corvid density and nest predation in relation to forest fragmentation. Ecology 73, 794-804.

Andrén, H., Angelstam, P., 1988. Elevated predation rates as an edge effect in habitat islands: experimental evidence. Ecology 69, 544-547.

Angelstam, P., 1986. Predation on ground-nesting birds' nests in relation to predator densities and habitat edge. Oikos 47, 365-373.

Barding, E.E., Nelson, T.A., 2008. Raccoons use habitat edges in northern Illinois. American Midland Naturalist 159, 394-402.

Berec, L., Angulo, E., Courchamp, F., 2007. Multiple Allee effects and population management. Trends in Ecology \& Evolution 22, 185-191.

Bohning-Gaese, K., Taper, M.L., Brown, J.H., 1993. Are declines in North American insectivorouos songbirds due to causes on the breeding range. Conservation Biology 7, 76-85.

Cantrell, R.S., Cosner, C., Fagan, W.F., 2001. How predator incursions affect critical patch size: the role of the functional response. American Naturalist 158 368-375.

Cantrell, R.S., Cosner, C., Fagan, W.F., 2002. Habitat edges and predator-prey interactions: effects on critical patch size. Mathematical Biosciences 175, 31-55.

Chalfoun, A.D., Thompson III, F.R., Ratnaswamy, M.J., 2002. Nest predators and fragmentation: A review and meta-analysis. Conservation Biology 16, 306-318.

Courchamp, F., Clutton-Brock, T., Grenfell, B., 1999. Inverse density dependence and the Allee effect. Trends in Ecology and Evolution 14, 405-410.

Davis, S.K., 2004. Area sensitivity in grassland passerines: effects of patch size, patch shape, and vegetation structure on bird abundance and occurrence in southern Saskatchewan. Auk 121, 1130-1145.

Deng, W.-H., Gao, W., 2005. Edge effects on nesting success of cavity-nesting birds in fragmented forests. Biological Conservation 126, 363-370.

Dijak, W.D., Thompson III, F.R., 2000. Landscape and edge effects on the distribution of mammalian predators in Missouri. Journal of Wildlife Management 64 209-216.

Donovan, T.M., Jones, P.W., Annand, E.M., Thompson III, F.R., 1997. Variation in local-scale edge effects: mechanisms and landscape context. Ecology 78, 2064 2075.

Fernández, C., Acosta, J.F., Abellá, G., López, F., Díaz, M., 2002. Complex edge effect fields as additive processes in patches of ecological systems. Ecological Modelling 149, 273-283.

Flaspohler, D.J., Temple, S.A., Rosenfield, R.N., 2001. Effects of forest edges on ovenbird demography in a managed forest landscape. Conservation Biology 15 173-183.

Fletcher Jr., R.J., 2005. Multiple edge effects and their implications in fragmented landscapes. Journal of Animal Ecology 74, 342-352.

Gascoigne, J.C., Lipcius, R.N., 2004. Allee effects driven by predation. Journal of Applied Ecology 41, 801-810.

Gates, J.E., Gysel, L.W., 1978. Avian nest dispersion and fledging success in field-forest ecotones. Ecology 59, 871-883.

Ghalambor, C.K., Martin, T.E., 2001. Fecundity-survival trade-offs and parental risktaking in birds. Science 292, 494-497.

Holling, C.S., 1959. Some characteristics of simple types of predation and parasitism Canadian Entomologist 91, 385-398.

Huhta, E. Jokimaki, J., Rahko, P. 1998. Distribution and reproductive success of the Pied Flycatcher Ficedula hypoleuca in relation to forest patch size and vegetation characteristics; the effect of scale. Ibis 140, 214-222.

Jaksic, F.M., Silva, S.I., Meserve, P.L., Gutiérrez, J.R., 1997. A long-term study of vertebrate predator responses to an El Nino (ENSO) disturbance in western South America. Oikos 78, 341-354.

Jeschke, J.M., Kopp, M., Tollrian, R., 2002. Predator functional responses: discriminating between handling and digesting prey. Ecological Monographs 72, 95-112.

Kays, R.W., Gompper, M.W., Ray, J.C., 2008. Landscape ecology of eastern coyotes based on large-scale estimates of abundance. Ecological Applications 18 1014-1027.

Keyser, A.J., Hill, G.E., Soehren, E.C., 1998. Effects of forest fragment size, nest density, and proximity to edge on the risk of predation to ground-nesting passerine birds. Conservation Biology 12, 986-994.

Lahti, D.C., 2001. The "edge effect on nest predation" hypothesis after twenty years. Biological Conservation 99, 365-374.

Lamberson, R.H., McKelvey, R., Noon, B.R., Voss, C., 1992. A dynamic analysis of northern spotted owl viability in a fragmented forest landscape. Conservation Biology 6, 505-512.

Levins, R., Schultz, B.B., 1996. Effects of density dependence, feedback and environmental sensitivity on correlations among predators, prey and plant resources models and practical implications. Journal of Animal Ecology 65, 802-812.

Lloyd, P., Martin, T.E., Redmond, R.L., Langner, U., Hart, M.M., 2005. Linking demographic effects of habitat fragmentation across landscapes to continental source-sink dynamics. Ecological Applications 15, 1504-1514.

Manolis, J.C., Andersen, D.E., Cuthbert, F.J., 2002. Edge effect on nesting success of ground nesting birds near regenerating clearcuts in a forest-dominated landscape. Auk 119, 955-970.
Martin, T.E., 1993. Nest predation and nest sites: new perspectives on old patterns Bioscience 43, 523-532.

Martin, T.E., Li, P., 1992. Life history traits of open- vs. cavity-nesting birds. Ecology $73,579-592$.

Marzluff, J.M., Millspaugh, J.J., Hurvitz, P., Handcock, M.S., 2005. Relating resources to a probabilistic measure of space use: forest fragments and Steller's jays. Ecology $85,1411-1427$

Matthews, A., Dickman, C.R., Major, R.E., 1999. The influence of fragment size and edge on nest predation in urban bushland. Ecography 22, 349-356.

Mayfield, H., 1975. Suggestions for calculating nest success. Wilson Bulletin 87, $456-466$.

Mazgajski, T.D., Rejt, L., 2005. Forest fragment size affects edge effect in nest predation-experiment with artificial nests. Polish Journal of Ecology 53, 233-242.

Miller, D.A., Grand, J.B., Fondell, T.E., Anthony, M., 2006. Predator functional response and prey survival: direct and indirect interactions affecting a marked prey population. Journal of Animal Ecology 75, 101-110.

Miller, D.A., Grand, J.B., Fondell, T.E., Anthony, M., 2007. Optimizing nest survival and female survival: consequences of nest site selection for Canada geese. Condor 109, 769-780.

Murica, C., 1995. Edge effects in fragmented forests: implications for conservation. Trends in Ecology and Evolution 10, 58-62.

Naef-Daenzer, B., Widmer, F., Nuber, M., 2001. Differential post-fledging survival of great and coal tits in relation to their condition and fledging date. Journal of Animal Ecology 70, 730-738.

Ostfeld, R.S., Jones, C.G., Wolff, J.O., 1996. Of mice and mast. Bioscience 46, 323-330.

Pasitschniak-Arts, M., Messier, F., 1995. Risk of predation on waterfowl nests in the Canadian prairies: effects of habitat edges and agricultural practices. Oikos 73 347-355.

Paton, P.W.C., 1994. The effect of edge on avian nest success-how strong is the evidence. Conservation Biology 8, 17-26.

Perkins, D.W., Vickery, P.D., Shriver, W.G., 2003. Spatial dynamics of source-sink habitats: effects on rare grassland birds. Journal of Wildlife Management 67, 588-599.

Picman, J., 1988. Experimental study of predation on eggs of ground-nesting birds: effects of habitat and nest distribution. Condor 90, 124-131.

Pulliam, H.R., Danielson, B.J., 1991. Sources, sinks, and habitat selection: a landscape perspective on population dynamics. American Naturalist 137, S50-S66.

Pulliam, H.R., 1988. Sources, sinks, and population regulation. American Naturalist $132,653-661$

Saunders, D.A., Hobbs, R.J., Margules, C.R., 1991. Biological consequences of ecosystem fragmentation: a review. Conservation Biology 5, 18-32.

Schaub, M., Pradel, R., 2004. Assessing the relative importance of different sources of mortality from recoveries of marked animals. Ecology 85, 930-938.

Schmidt, K.A., Goheen, J.R., Naumann, R., 2001. Incidental nest predation in songbirds: behavioral indicators detect ecological scales and processes. Ecology 82 2937-2947.

Seymour, A.S., Harris, S., Ralston, C., White, P.C.L., 2003. Factors influencing the nesting success of lapwings Vanellus vanellus and fox Vulpes vulpes behaviour in lapwing nesting sites. Bird Study 50, 39-46.

Seymour, A.S., Harris, S., White, P.C.L., 2004. Potential effects of reserve size on incidental nest predation by red foxes Vulpes vulpes. Ecological Modelling 175 , 101-114.

Small, M.F., Hunter, M.L., 1988. Forest fragmentation and avian nest predation in forested landscapes. Oecologia 76, 62-64.

Söderström, B., Part, T., Ryden, J., 1998. Different nest predator faunas and nest predation risk on ground and shrub nests at forest ecotones: an experiment and a review. Oecologia 117, 108-118.

Storch, I., Woitke, E., Krieger, S., 2005. Landscape-scale edge effect in predation risk in forest-farmland mosaics of central Europe. Landscape Ecology 20, 927-940.

Thompson, F.R., Donovan, T.M., DeGraaf, R.M., Faaborg, J., Robinson, S.K., 2002. A multi-scale perspective of the effects of forest fragmentation on birds in eastern forests. Studies in Avian Biology 25, 8-19.

Vergara, P.M., 2005. Depredación de nidos en bordes de bosque en una Reserva Nacional de la Cordillera de la Costa de la Región del Maule. In: Smith-Ramirez, C., Armesto, J.J., Valdovinos, C. (Eds.), Historia, Biodiversidad y Ecología de los Bosques Costeros de Chile. Editorial Universitaria, Santiago, Chile, pp. 578-584.

Vickery, P.D., Hunter, M.L., Wells, J.W., 1992. Evidence of incidental nest predation and its effects on nests of threatened grassland birds. Oikos 63, 281-288.

Watkinson, A.R., Sutherland, W.J., 1995. Sources, sinks and pseudo-sinks. Journal of Animal Ecology 64, 126-130.

Wiebe, K.L., Martin, K., 1998. Age-specific patterns of reproduction in ptarmigan. Ibis $140,14-24$

Wiens, J.A., 1992. Ecological flows across landscape boundaries: a conceptual overview. In: Hansen, A.J., di Castri, F. (Eds.), Landscape Boundaries: Consequences for Biotic Diversity and Ecological Flows. Springer-Verlag, Berlin, pp. 218-235.

Wilcove, D.S., 1985. Nest predation in forest tracts and the decline of migratory songbirds. Ecology 66, 1211-1214.

Yahner, R.H., 1996. Forest fragmentation, artificial nest studies, and predator abundance. Conservation Biology 10, 672-673.

Zanette, L., Doyle, P., Tremont, S.M., 2000. Food shortage in small fragments: evidence from an area-sensitive passerine. Ecology 81, 1654-1666. 